\title{
MODEL OF NEUTRALITY IN AN OLIGOPOLY IN TELECOMMUNICATIONS
}

\author{
OCTAVIO JOSÉ SALCEDO PARRA ${ }^{1,2}$, DAVID ANDRÉS CÁRDENAS D ${ }^{2}$. \& MIGUEL J. ESPITIA R. ${ }^{1}$ \\ ${ }^{1}$ Faculty of Engineering, Universidad Distrital Francisco José de Caldas, Bogotá, Colombia \\ ${ }^{2}$ Faculty of Engineering, Universidad Nacional de Colombia, Bogotá D.C., Colombia
}

ABSTRACT
The whole idea of this work is to determine with respect to the existing regulations which could be improved or that could
BE determined so that a telecommunications "SME" can benefit at the operational level.
KEYWD: Games Theory, Neutrality, Oligopoly \& Telecommunications

Received: Sep 16, 2020; Accepted: Oct 06, 2020; Pbublished: Nov 11, 2020; Paper Id.: IJMPERDOCT202043

\section{INTRODUCTION}

The present work aims to illustrate two basic topics, first to evidence through the analysis of previous studies; what have been the problems that have for a small telecommunications carrier for to be able to enter the business in an elite way and be able to compete with the service carriers that command the issue at the level of coverage and customers in some society, additional determine what would be the regulations that govern this type of companies for to be able to perform a job launching a service about a certain group of inhabitants in a society additionally visualize a perspective psychosocial what would be the pros and cons that have the nascent carriers to be able to enter the business.(1)

The whole idea of this work is to determine with respect to existing regulations that could be improved or that could determine for a telecommunications "SME" can be benefited at the operational level for this model.

\section{PREVIOUS STUDIES}

\subsection{Definition of Oligopoly}

The oligopoly term or oligopolistic refers to a been in a market situation where people or the companies that are competing in this type of business the term becomes clearer when it should be emphasize that in an oligopoly only a few companies are those that have control over the business and provide the service of compartiKorolev State Aerospace University, Samara, Russian, it is taken into account that clean competition at the price level and more due to that what one does affects the other.

Korolev State Aerospace University, validates a study where he implements a model to explain the behavior of an oligopolistic market in terms general (1) of this behavior can be concluded what next (2).

\subsection{An Investigation to Determine the Process of a Research of this Kind}

The structures of oligopoly goods markets (previous modeling based on linear functions of demand and linear cost functions of agents); using linearly and power demand functions under of nonlinear cost functions for the identification of greater market precision research balances the analytical model of a structure could be developed not market with the reaction of Cournot, as the analytical models of hierarchical structures in the form of an 
asymmetric equilibrium with one or several leaders of Stackelberg and a Stackelberg balance with reflection informative of the leaders. The structure of the Cournot market nonhierarchical is characterized by the asymmetric distribution of quotas market, and the market is restructured for profit of the agents that have lower growth the rates of the cost functions. However, for models of the real markets, the resulting asymmetry is negligible due to the two factors, namely the small influence of the cost component in the equilibrium structure in comparison with the demand component (the parameters of these functions are incommensurable quantitatively) and the small differences between the growth rates of the cost functions of the predominant agents that make an identical product and therefore of use common technologies the structure of the Stackelberg market hierarchical predetermines the asymmetry considerably greater of market distribution among agents because of the additional influence of the addition of conjectural variations in the resulting balance, which is commensurable with the function demand parameters. Through the introduction of nonlinear cost functions in the models of developed reaction of the agents, we have taken into account the expansion effect in conjectural variations: the unfixed conjectural variations reflect the impact of the resulting market structure and the technologies of the agents (cost functions) in the reaction rates of the agents. And the structure of the resulting equilibrium market should be shifted towards conjectural agents of sensitization higher level and redistributed among the agents of lower level awareness for the benefit of who have the effect of positive expansion. In the case of Stackelberg equilibrium with the informative reflection of the leaders, the conjecture variations exert even greater influence, redistributing the market to the benefit of the capital. The leaders of sensitization to scale. At context of the selection of the strategy of the companies who work in oligopolistic markets, developed countries complex of models gives a formal description of balances for different (symmetric and asymmetric) sale of market structures by varying the types of reactions and levels of conjectural awareness. The dynamic economic model of the telecommunications market, The Volga region has proven that this market is an oligopoly with the functions of energy prices in the early stage development and the linear price in recent years, have also produced cost functions if the agents with different expansive effects. The analysis numeric of the calculated balance within the models from reactions of agents have shown that the Cournot model is more suitable for the market of telecommunications in the Volga region 2013. This fact implicitly indicates that agents have stable actions in stable market conditions. Structural modeling MARKET OLIGOPOLY 347 has left to substantially influence the profit increase of market agents, in contrast to the fast stage market growth and the redistribution of market shares market between the agents in $2004-2008$. Therefore, a promising strategy for agents consists of a redistribution market using technological advance to achieve the expansion effect that exists in the services market of Internet (4).

\section{MODEL}

The model for this analysis will be based on several factors and analyzing the following factors:

\subsection{The Players. In these Models, 3 types will be Considered of Players}

- An oligopoly, generating competition in the market of Carrier telecommunications, which provide the service of telecommunications at a general level about users final

- Two providers in general who are the leaders in the telecommunications service nationwide

- The users who receive the telecommunications service by the Carrier

\subsection{No Networking Neutrality}


- NN1: For the first case of no neutrality due to that on the part of the two suppliers the market founds closed not allowing competition from other minor carriers could enter the business of Telecommunications in a competitive manner. (6)

- NN2: due to the control that was presented on this market, users did not have the way to count on other services and basically fit the exposed for the Carrier constituents.

\subsection{Network Neutrality}

Net neutrality is evaluated when the Carrier of telecommunications regardless of origin and other characteristics can enter the telecommunications market no hassle and users may have more options to choose the service to use.

\subsection{The rules}

This model consists of two interconnected providers that compete on prices, for customers. This with the reason of be able to enter the telecommunications business without any kind of embarrassment (6).

In this model, it is considered a model with two Carrier of telecommunications denoted by A and B, two classes of customers $\mathrm{Y}$ and $\mathrm{G}$ and a multitude of customers normalized to zero where clients $\mathrm{x}[0,1]$. Normalization is necessary of consumers or customers to 1 to facilitate the analysis of the model., consumers or customers are distributed in a straight line from 0 to 1 where the ends of the line are find the Carrier of telecommunications The client in the time to make the decision on which service to take represents as $\mathrm{x}$ in this way is represented by the following functions which were taken according to the analysis I carry out Evaluation of Network Neutrality Scenarios from Sthefania Moreno Reina.

Model 1: $Y(X)=X G(X)=1 X$

Model 2: $\mathrm{A}(\mathrm{X})=\mathrm{XB}(\mathrm{x})=1+\mathrm{X}$

\section{NO NETWORK NEUTRALITY MODEL}

\subsection{NN1 Case}

For the first case of no neutrality, it can be noticed that the customers that each of the Carrier has is not what is expected given that for the Carrier compared with $\mathrm{B}$ the clients are older this is due to the irregularity that is presented in the business regulations Telecommunications (6)

To carry out the analysis, we assumed that the services that clients and by QoS equals z. Once the Carrier define the services, the clients must make the decision of take the service Since this decision directly affects to the profits or interests of each one of the Carrier and be or B these gains and others will be taken and represented by an F indicator because what each the Carrier wants is to cover as such all the masses of clients or consumers.

$\mathbf{F}(\mathbf{y}):$ (1if $Y$ pays to $Z$; or 0 if $Y$ does not pay to $Z$ )

$\mathbf{F}(\mathrm{g})$ : (1if $\mathrm{G}$ pays to $\mathrm{Z}$; or 0 if $\mathrm{G}$ does not pay to $\mathrm{Z}$ )

In this way each of the telecommunications Carrier will offer a communication service for all users in which it would differ basically in that due to the distribution that, if any customer takes a service telecommunication with B, there will be a notation regarding coverage because you have the possibility of a best service for its position within the market regarding $\mathrm{B}$ 


\subsection{NN2 Case}

For this case of non-neutrality lies in the later subject which is at the moment of no competition at the level of service and customers should be coupled to what is allowed basically what is in the market A completely taking the market and B out of possibilities to enter to the telecommunications market for this case it represents the same as the previous part where $\mathrm{J}$ would be the service it offers and in response to this is determine if customers will pay that price because they do not have more options as such, B does not enter the game due to the national regulations that do not allow it. (6)

$\mathbf{F}(\mathbf{y}):$ ( 1 if $Y$ pays to $J$ or 0 if $Y$ does not pay to $J$ )

$\mathbf{F}(\mathrm{g})$ : (1 if $\mathrm{G}$ pays to $\mathrm{J}$ or 0 if $\mathrm{G}$ does not pay to $\mathrm{J})$

In this way it is shown that $\mathrm{J}$ can be paid for any of the users according to the need of each of customers, while $\mathrm{B}$ taking the opportunity not can enter the market and therefore cannot compete at the level of rates and sales.

\section{DECISION MAKING: NETWORK NEUTRALITY}

\subsection{Rates for the Service and Communication of the Carrier}

Making a respective analysis of demand and verifying each of the interests of the Carrier in analysis within an equal environment you will have two $\mathrm{T}$ options where they define an equal cost and another can define different rates where $\mathrm{M}$ for $\mathrm{B}$ and $\mathrm{N}$ for $\mathrm{A}$.

\subsection{Coverage Provided between Carrier}

For this case in special the subject is not linked to something that as such the Carrier of telecommunications can determine the issue of economic capacity to provide the respective coverage through antennas and additional the subject of how much the state can allow the Carrier in question diversify and provide the service.

\section{DECISION MAKING: NO NETWORK NEUTRALITY}

Cases to Consider:

A. Case 1: NN1: entry disadvantage for a Carrier less

B. Case 2: NN2: the only service that is available is the one provides is for the Carrier

\section{Case NN1}

Basically, in this case of non-neutrality is when there when there is a drawback over competition as such between and B since the first one has priority over the other this shows that as such the service is given by the coverage that each Carrier can support.

\section{Coverage Provided between Carriers.}

This decision does not depend on the Carrier directly alone if you talk about the economic part to make the assembly of infrastructure and additional permissions by regulations have to impose the service in a particular area

For the above, the following cases will be presented:

Case 1: $\mathrm{FY}=\mathrm{FG}=1$ : When $\mathrm{Y} \mathrm{G}$ decide to pay the respective rates In this case each of the customers takes the respective service for which is in the same economic situation to say it somehow about the market 
Case 2: $\mathrm{IY}=0 ; \mathrm{IG}=0$ : In this case, none of the content providers decide that neither of the two carrier have no growth parameters.

\section{E. Case NN2}

Basically in this case of non-neutrality is when there when there is a disadvantage over competition as such between and B since the only existing services are the that at the time the first Carrier can offer that in the second is not at stake.

\section{F. Tariff prices for the communication service of the carriers}

Making a respective analysis of demand and verifying each of the interests of the carriers is informed that the definition of each of the rates can be handled by the Carrier niche in the market and can define costs of or of collection towards the masses of consumers for this case B

For the above, the following cases will be presented

Case 1: $F Y=F G=1$ : When $Y G$ decide to take the service with that Carrier which means that this Carrier telecommunications will have a respective gain to own for growth or how to make a profit complete

Case 2: $\mathrm{IY}=0 ; \mathrm{IG}=0$ : In this case, problem for the Carrier given that they will not have respective income.

\section{DISCUSSION}

How could it be evaluated in each of the scenarios on which the article was founded, which has account the capacity that the Carrier has over the $\mathrm{B}$, preferences and regulations that do not allow a Balanced competition due to interests below rope and regulations that favor a single party companies of telecommunications, leaving small competitors outside. For the above, they were taken into account in cases of no neutrality $\mathrm{FY}=\mathrm{FG}=1$ and $\mathrm{y}=\mathrm{IG}=1$ where it is evaluated at the time of each client takes the service no matter the respective scenarios or changes that arise. First, in the case of NN1 you can observe the Next, each of the players is taken representing them in an equal way to each one as if they had the same strength in the market or that is to say the same opportunities and within the analysis of each case of no neutrality is reported that there are several drawbacks since it is observed the equality in when $\mathrm{F}(\mathrm{Y})=1$ at a general level given that the Carrier leaders or with greater strength have greater opportunity due to the purchasing power they have while the B or small Carrier do not have the same opportunities represented in the case of NN2 where we only have into account only one carrier in that case the leader or the leaders as such in the oligopoly where it is evidenced with IY $=0$; IG $=0$, and due to the purchasing power they have do not allow any kind of competition or take care of stay with all the mass of customers possible, but also it could be analyzed that for these clients sometimes being with the older Carrier is not what is recommended because a lot of customers cannot give an optimal service additional, which is why we proceed to search for other options like that of the smallest Carrier.

In the case of NN2, Carrier constituents are taken into account only basically is $=1 \mathrm{in}$ all aspects and focuses on thinking how each client could enter to have a service only with what is offered without having so many options basically 100 of the total masses of clients is to buy plans and services issues to consider, basically analyzing the Carrier's economy and entering analyze if these could have the form to meet needs, moments within the business that were validated or brought was the issue of the coverage of each Carrier in where it starts to work or to validate the purchasing power that have each of the companies and additional the issue of rates which is interesting to analyze because the fees for service charges may change depending on the amount of competition you have and the interests and vision that Carrier has in the 
market where the first case as such is defined $\mathrm{I}(\mathrm{G})+\mathrm{I}(\mathrm{Y})=1$ where 1 belongs to the complete mass this depends on a factor $\mathrm{X}$ the which is linked to the purchasing power of the company.

As Haring, J.R., Weisman, D.L. (5) speak in their article of 1993 where it is reported that after performing a telecommunications market analysis in the states united is a percentage of almost 70 of the total over 100 of the irregularities that are presented on the regulations governing telecommunications in the country are informs that it is agreed in the results given that after to validate the simple relationships or options that can be submit is reported to cover the same where it is evident that the regulations generate opportunities and irregularities due to money that the company can offer.

On the other hand Geras KIN (3) in his article of 2014 exposes the way in which a market can be developed by Cournot and more but within the conclusions of this work you can detonate the discomfort that you have due to the services, validating previous works and $\mathrm{He}$ finds that the problems lie in a relationship of 70:30 and 80:20 where it is evident that the main problem is the lack of normativity.

\section{CONCLUSIONS}

A. A way to finish and have an economic education perfect in the telecommunications business is without import precedence and other lets between any carrier to offer service due to this way it is You can have options for customers and the business can be diversify and generate a high QoS because it does not will have no congestion on the network

B. When the respective determinant was made for each neutrality case where it was determined that $F$ and $J=1$ is when they really recognize any of the carrier as equal competitors in the market but what is due keep in mind is that the fact of having equality does not mean that you are going to have the same opportunities but as such A carrier A with many customers at some point can collapse generating dissatisfaction a pessimistic service

\section{REFERENCES}

1. Lam, P.-L.Transition to competition in Hong Kong's local telephone industry Telecommunications Policy, 1996, 20, 517-529

2. Hewett, The global telecoms industry what happens now? Journal of the Communications Network, 2003, 2, 32-34

3. Hewett, J.The global telecoms industry - What happens now?Telecommunications Journal of Australia, 2003, 53, 55-58+71

4. Geraskin, M. y Chkhartishvili, A.Structural modeling of oligopoly market under the nonlinear functions of demand and agents costs Automation and Remote Control, 2017, 78, 332-348

5. Haring, J. y Weisman, D.Dominance, nondominance and the public interest in telecommunications regulation Telecommunications Policy, 1993, 17, 98-106

6. Evaluación de Escenarios de Neutralidad de Red,realizado por Sthefania Moreno Reina 